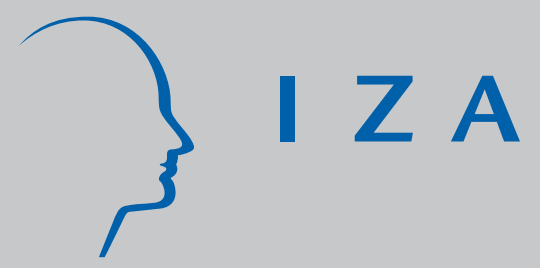

IZA DP No. 1035

Estimates of a Labour Supply Function Using Alternative Measures of Hours of Work

N. Anders Klevmarken

February 2004 


\title{
Estimates of a Labour Supply Function Using Alternative Measures of Hours of Work
}

\author{
N. Anders Klevmarken \\ Uppsala University and IZA Bonn
}

Discussion Paper No. 1035

February 2004

\author{
IZA \\ P.O. Box 7240 \\ 53072 Bonn \\ Germany \\ Phone: +49-228-3894-0 \\ Fax: +49-228-3894-180 \\ Email: iza@iza.org
}

\begin{abstract}
Any opinions expressed here are those of the author(s) and not those of the institute. Research disseminated by IZA may include views on policy, but the institute itself takes no institutional policy positions.

The Institute for the Study of Labor (IZA) in Bonn is a local and virtual international research center and a place of communication between science, politics and business. IZA is an independent nonprofit company supported by Deutsche Post World Net. The center is associated with the University of Bonn and offers a stimulating research environment through its research networks, research support, and visitors and doctoral programs. IZA engages in (i) original and internationally competitive research in all fields of labor economics, (ii) development of policy concepts, and (iii) dissemination of research results and concepts to the interested public.
\end{abstract}

IZA Discussion Papers often represent preliminary work and are circulated to encourage discussion. Citation of such a paper should account for its provisional character. A revised version may be available on the IZA website (www.iza.org) or directly from the author. 
IZA Discussion Paper No. 1035

February 2004

\section{ABSTRACT}

\section{Estimates of a Labour Supply Function Using Alternative Measures of Hours of Work*}

Depending on data source, estimates of hours of work give widely different results both as to level and change. In this paper three alternative measures of hours worked are used to estimate a simple labour supply function to investigate if estimated wage rate and income effects are data dependent as well. The measures used include those from time-use surveys and those from regular surveys. The latter are based on the responses to a question about normal weekly hours of market work. The results suggest that estimates of the wage rate effects become much smaller when measures of normal hours are used compared to data collected for a well-defined time period close to the date of interview, such as time-use data. The income effects appear less sensitive to the choice of data.

JEL Classification: J22, C81, C39

Keywords: hours of work, labour supply, time-use, measurement errors

N. Anders Klevmarken

Department of Economics

Uppsala University

P.O. Box 513

75120 Uppsala

Sweden

Tel.: +46184712386

Fax: +46184711478

Email: anders.klevmarken@nek.uu.se

\footnotetext{
* Useful comments and suggestions from Dan Hamermesh, Matias Eklöf, Daniel Hallberg and participants at the IZA $2^{\text {nd }}$ Conference of the International Research Consortium in the Economics of Time Use, St. Gerlach, May 26-27 are gratefully acknowledged.
} 


\section{Introduction}

Time-use studies have been motivated by their ability to give data for analysis and valuation of household work, but also because they give information about leisure (the ultimate utility yielding activities?), commuting and travel behavior, etc. In addition most time-use surveys have data on hours of work. One could argue that time-use studies, taking various deviations from normal work hours into account, give better data on hours actually worked as contrasted with the number of contracted hours. Time-use data also have the potential to improve the analysis of labour supply by explicitly including competing activities in the home, and making feasible studies of gender differences in market and non-market work, and thus also improving our understanding of female labour supply. However, most labour supply studies have used more conventional data sources such as labour force surveys. ${ }^{1}$

Simple comparisons of levels and trends in hours worked demonstrate that different measures and data sources tell different stories (see Klevmarken, 1999 and below). No previous study has, however, used a common data set to evaluate how the choice of measure will influence estimates of wage rate elasticities and income elasticities in labour supply functions. This is the topic of this paper. These elasticities are of key importance in economic policy, and they have, for instance, guided politicians in designing new tax systems.

Section 2 below gives a survey of the few comparisons of time-use estimates and more conventional survey estimates that can be found in the literature and also presents some stylized facts about average weekly hours of work in Sweden obtained from different sources. There follow in Section 3 a more detailed account for the data used in this study, in section 4 a specification of the economic and econometric models used, and in Section 5 the empirical results. A few concluding remarks end the paper. 


\section{Measures of market time.}

Conventional measures of market time based on survey questions about normal weekly hours tend to give empirical frequency distributions which have pronounced peaks at full-time hours for men and at half-time and full-time hours for women. The observed high concentration at peak hours is probably exaggerated. There are good reasons to believe that many respondents report their contracted number of hours disregarding or forgetting any nonwork episodes at work and any irregular overtime work. Even if asked explicitly about secondary work, they might find it difficult to report hours retrospectively, in particular if the respondent only works intermittently in this job. In general, those who have irregular work hours will find it difficult to respond to questions about normal hours. Time-use diaries are, however, normally collected such that meals, coffee breaks and other work breaks, over-time and time on secondary jobs are carefully recorded. In particular, if a time diary is given in a "yesterday interview" and not in a leave-behind diary, its sequential nature makes it difficult to falsify. ${ }^{2}$ Time-use surveys also have the advantage of giving data on travel to and from work. Sometimes it is desirable to add commuting time to pure market work time.

Figure 1 (borrowed from Klevmarken, 1999) illustrates the differences between data based on questions about current hours per week including overtime and secondary jobs ("survey data") and time-use data from the same samples of people. Data were obtained from the Swedish Household Panel Surveys HUS (Klevmarken and Olovsson 1993, Flood et.al 1997). The time-use data distributions are much smoother and have a larger variance. The explanation is partly that just given, but also arise from the noisiness of time-use data due to 
the fact that only a few days are observed for each respondent. (One might also note that independently of data source the distribution for women has become more alike that of men.)

Carlin and Flood(1997) compared estimates of male labour supply from time-use data with those from conventional survey data using a so called double-hurdle model. Referring to previous studies they noted that the presence of young children normally decreases work hours for women while the effect for males has typically become insignificant or weakly positive. Sweden's active policy to bring women into the labour market and involve fathers more actively in the care of children, and independent evidence that this policy to some extent has been successful, suggested that one might expect a negative effect on labour supply also for Swedish males. They found no significant effect of the presence of young children when the estimates were based on the responses to the survey question about normal weekly hours, but they found a negative effect when they used time-use data. The double-hurdle model suggested that the largest share of this effect came from fathers losing entire days rather than reducing hours of work when working. The explanation to this difference in results is thus that time-use data recorded temporary, unusual and unexpected episodes of absence from work (in this case probably because kids became sick), while this was not the case with data based on responses to the question about normal hours of work. In their study the number of children in different age groups were treated as exogenously given. Using a Hausman test they could not reject this assumption, but there is still a question as to what would happen if children were endogenous to the labour supply decisions. For the other explanatory variables the parameter estimates did not depend much on whether time-use or survey data were used.

Depending on the importance of breaks, nonwork at work, overtime and secondary jobs and irregular jobs, there are reasons to expect systematic differences in estimates of average work 
hours from time-use diaries compared to conventional labour force surveys. Juster and Stafford(1991) report that "conventional respondent reports of labour supply seriously overstate the amount of hours actually supplied to the market" (p. 486). They also claim that conventional Current Population Survey estimates underestimated the 1965-1981 decline in work hours (compared to time-use estimates). This conclusion was, however, questioned by Leete and Schor(1994) who suggested that the Michigan Study, only measuring weekly hours, did not adequately reflect the substantial rise in weeks worked per year found in the CPS. ${ }^{3}$ Leete and Schor(1994) found support for the "time-squeeze" hypothesis. According to their results Americans worked longer hours and enjoyed less leisure at the end of the period.

Table 1 compares a number of different measures of weekly hours worked for Sweden. There are three groups of estimates: survey-type estimates from the HUS surveys, estimates from the official labour force surveys and time-use estimates. They all differ in level as well as in rate of change. The official estimates give an average of about 35 hours per week for all men in work including those who are temporarily absent, and about 26 hours for women. These estimates show a small decrease in hours for men and a small increase for women. The conceptually closer comparison is the HUS data estimates for normal hours including overtime and secondary jobs. For men they show a small increase from 41.8 to 42.5 hours, and for females there is an increase from 35 to 37.5 hours. The difference in the changes between the two types of estimates is probably on the borderline of being significant for males but clearly significant for females. The time-use estimates show a completely different picture. The rows "All” include everybody, not only those in the labour force, and thus give much lower mean estimates. To obtain something which is closer to the "survey estimates" the estimates on the last and third last rows in the table were restricted to those who had responded positive "normal hours". Excluding breaks these estimates are still much lower 
than the "survey estimates", but more importantly they show a very strong increase in hours worked. Independent sources indicate that sickness absence decreased drastically and overtime increased in this period. Unemployment was much higher in 1993 compared to 1984, but judging from the time-use estimates for "All" this did not influence average work hours much! More work is needed to understand why all these estimates differ. One hypothesis is that time-use estimates more closely measure hours actually worked and that they are more sensitive to changes in the market than measures based on traditional survey questions. Given that actual hours are more relevant, for instance in measures of productivity, than normal hours or contracted hours, survey-type measures might be misleading.

\section{Data sources}

Data used in the analysis to follow below come from the 1993 wave of the Swedish household panel survey HUS that included a time-use survey (Flood et al 1997). The design was such that the regular panel survey was executed during the spring of 1993. Most of the interviews were done in the period February - April. In households with two spouses both were interviewed. ${ }^{4}$ Because almost everyone in Sweden is retired at the age of 65 the sample used in this paper was limited to the age bracket $18-64 .^{5}$

The time-use survey was administered in separate interviews during the period March 1993 February 1994. Each respondent was asked to participate in two telephone interviews that were randomly allocated over this period, such that one was on a week day and the other on a weekend day. One was done during the winter half and the other during the summer half of the year. 
Time-use data were collected by the yesterday method, i e each respondent was called up the day after the selected day and asked to recapitulate what he or she did in that day ( 24 hours). Activities were recorded in free format and in the wording of the respondent and afterwards coded into activities. For each time span the respondent could give two activities, one main and one secondary activity. In the analysis of this paper hours of market work include the sum of time in both the primary and secondary activity "market work", but excludes breaks and job related trips.

In these time-use interviews the respondents were also asked how many hours they worked in the market in the week preceding the week of the interview.

Data on age, gender, schooling, housing, etc, were obtained from the main survey interview. The gross wage rate estimates were also obtained from this interview. They originate from a sequence of questions about hourly, weekly or monthly pay. The respondent could chose to respond by either mode. A large majority were paid by the month. For reasons to be explained later there are two different wage rate estimates, one hourly wage rate and one monthly wage rate. The estimate of the hourly wage rate was obtained by dividing earnings by an estimate of hours worked. The estimate used was the response to the question about normal weekly hours ${ }^{6}$ multiplied by a factor that depended on the time-span of the earnings measure. This factor was 1 for weekly earnings, 2 for bi-weekly earnings and 4.3 for monthly earnings.

The monthly rate is an attempt to estimate a monthly pay for the full time of 38 hours. For the few respondents who had weekly or bi-weekly pay it was multiplied by 4.3 and 2.15 respectively. For those who responded by an annual labour income it was divided by 12 , 
while an hourly wage rate was multiplied by $4.3 * 38$. These estimates as well as the direct survey response for those who were paid by the month would be misleading estimates if the respondent worked part-time or longer hours than normal full-time. For this reason the estimates of the monthly pay were adjusted by the ratio " 38 /normal weekly hours" if normal weekly hours were less than 31 hours or more than 44 hours. This monthly wage rate is thus less sensitive to measurement errors in normal weekly hours than the estimate of the hourly wage rate.

To estimate a labour supply function measures of the marginal tax rate and virtual income are needed. Unfortunately the income and tax data in the 1993 HUS wave refer to the year 1992. However, in the 1996 wave register data on 1993 incomes were added to the survey data. These data could be used to compute virtual income for those respondents that participated in both waves and gave us permission in 1996 to collect register data. This implies though a major reduction in sample size as demonstrated by the following numbers.

Number of respondents below the age of 65 with information about,

Basic demographics

Time-use from first interview

Time-use from second interview

Annual work hours

Hourly wage rate

Virtual income 1993
3522

2268

2669

2673

3392

1593 
Using the virtual income measure thus results in a partial nonresponse of about two thirds of the original sample, and it is not likely that it is random. On the contrary, informal inspection suggests that people who work in the market and in particular full-time workers are overrepresented in the reduced sample. This is unfortunate for any inference to the Swedish population below 65 years of age, but the reduced sample might still be useful in evaluating the relative magnitude of incentive effects due to alternative measures of hours of work.

To reduce partial nonresponse missing virtual incomes were imputed with a hot deck imputation technique. Using the share of the sample with nonmissing virtual income observations a regression was run for each gender of virtual income on the following variables: Net income in 1992, weeks worked in 1992, hourly wage rate in 1993, if unemployed or not in the labour force at the time of the main interview 1993, tax assessed value of owner occupied house ${ }^{7}$, age, age squared, if health problem, number of adults in the household, number of children in the household, years of schooling and annual work hours. The imputation procedure was bootstrapped and the number of observations contributing to the regression varied a little from one bootstrap draw to another but was typically around 400 for each gender. The regression R-square was usually in the range $0.30-0.35$. For each sample member the prediction from the regression was computed. For observations with missing virtual income a nearest neighbor was found among nonmissing observations based on the least distance between the predictions from the regression. Depending on the bootstrap sample about 200 observations were imputed for each gender. Thus about one third of the observations have imputed virtual income data.

In 1992 the income tax system had two brackets. In the first there was only a municipal tax of approximately $30 \%$ and above a certain threshold there was an additional state tax of $20 \%$. 
The municipal tax was decided locally and thus varied from one municipal to another, but because our data include information about where the respondent lived this was not a problem. To know if the state tax applied to a respondent we need to know the respondent's taxable labour income for 1993. This information was only available for the reduced sample. When the 1993 taxable labour income was missing it was estimated by the product of the estimates of annual hours worked and the hourly wage rate.

Following the definition in Blundell and MaCurdy (1999) virtual income was computed as the sum of capital income and the income obtained when the respondent's budget segment is extended to zero hours of work. Only the rules of the income tax system were considered in these computations, while nontaxable transfers were neglected. ${ }^{8}$ Capital incomes are taxed at a flat $30 \%$ rate in Sweden. The base of this tax does not only include interest and dividends but also realized capital gains. In the definition of virtual income one might like to exclude capital gains. Unfortunately, there is no information about capital gains for 1993 in the data source. To check for the sensitivity of the results to the definition of virtual income some models were also estimated with capital incomes deleted from virtual income. The wage rate effects were not much influenced by this change, while some income effects moved a little closer to zero. The disadvantage in using this second definition is, of course, that interest and dividend incomes are not included. The results presented below will be based on income data including capital incomes.

In summary, the following measures of hours of work have been used in the analytical part of this study:

1. Time-use estimates of hours of work in a designated day. 
2. Hours worked last week from the time-use survey.

3. Annual hours of work $=$ normal weekly hours $* 4,3 *$ months with market work as main activity.

Tables 2 and 3 give the pair-wise correlation between these measures for males and females. The first part of these two tables includes correlation coefficients when non-market work is included as a zero observation, while the second part only includes observations of individuals that worked. Week hours refer to hours worked last week collected jointly with time-use data. They are reported separately for the first and second time-use interview. True time-use data have been separated according to weekday and weekend. When observations of no market work are included most correlation coefficients are in the range $0.4-0.6$. When they are excluded the correlations drop a little. The correlations between these measures are thus not very high, reflecting the fact that there is a large amount of short-term variability in the behavior of a single individual. Not even the correlation between the same measure of hours worked last week at two different occasions exceeds 0.5 .

It is also clear from these tables that the amount of market work done during weekends is almost uncorrelated with the amount done in weekdays. These simple correlations neither suggest that weekend work is a substitute for weekday work, nor that those who work long hours in total also work in weekends. The share that reported any work in weekends was about 20 per cent among men and 14 per cent among women (Table 4). Including those who did not work at all in a designated day, men worked on average 1.2 hours per day on weekends and women 0.8 hours. $^{9}$

\section{Economic and econometric models}


For the purpose of this paper a simple economic model that has been used in previous work will be needed. Taking the income tax system into account we will use the following simple model,

$$
h=\beta_{0}+\beta_{1}[w(1-\operatorname{mtax})]+\beta_{2} y+\varepsilon_{h}
$$

where $\mathrm{h}$ is hours of work, $\mathrm{w}$ the hourly wage rate, $\operatorname{mtax}$ the marginal income tax rate, $\mathrm{y}$ virtual income and $\varepsilon$ a random error. Both mtax and y will in this model depend on hours of work and they are thus endogenous. An alternative specification also used in previous research is to replace the marginal net wage rate with its $\log , \ln (\mathrm{w}(1-\mathrm{mtax}))$. This model variant has also been estimated in a few cases. The numerical estimates of course changed, but the substantive results were almost the same as for the model above. To save space they are not reported below.

The interpretation of the labour supply function (1) as the outcome of a behavioral model assuming utility maximization is discussed in Blundell and MaCurdy (1999).

Because the tax system operates on an annual basis it is natural to think of $h$ as the annual hours of work. Most measures available however span a much shorter time period. The HUS time-use data only give information for at most two days per respondent and other survey measures have a week as their reference period. In the HUS time-use survey the two measurement occasions were randomly chosen among all days of the year $1993 .{ }^{10}$ In principle one could thus use the sampling weights and for each respondent estimate the annual hours of work, although this estimate would of course become very uncertain. With the sampling design used all work days had the same selection probability, and all weekend days also the 
same selection probability. We would thus get an estimate of the total number of work hours on each type of day by simply multiplying by the number of workdays and the number of weekend days respectively. In the analysis below we have chosen not to multiply by these constants but to use the observed hours per day and model potential workday/weekend differences in labour supply. The reason for this choice is that we would otherwise loose the respondents who only participated in one of the two time-use interviews.

Analogously for the measure of hours worked last week, we could blow them up to an annual level but can as well use the original weekly hours and assume that the constant sampling weight is absorbed into the parameters of the labour supply function. In these two cases one might thus hope that variations in hours across respondents because of the sampling design will capture some of the variation in hours during a year.

For the measure "normal weekly hours worked" there is no similar inference. In this case it is a matter of interpretation of "normal". Did the respondents average over a year, and if they did which year? Or did they interpret "normal" as the contracted hours at the time of the interview? With this measure we will most likely miss the variation in hours worked due to the fact that all respondents did not work all year or switched from part-time to full-time or vice versa during the course of the year 1993. This measure is neither likely to capture absence due to sickness, child care and other irregular decreases and increases in work hours. We try to capture part of the variation across the year by using survey information about months with market work in 1993.

\section{$\underline{\text { Econometric specification }}$}


Only for respondents who worked it is possible to observe a wage rate. The well-known selectivity problem in the estimation of a labour supply function will be handled in this paper by a Heckit approach.

Taking into account that most respondents contribute five observations, two "hours of work last week", one time-use estimate of hours of work in a weekday, one time-use estimate of hours of work in a weekend, and one annual hours observation, we will specify the following five equation model,

$$
\begin{aligned}
& h_{11}=\beta_{01}+\beta_{11}[w(1-\text { mtax })]+\beta_{21} y+\beta_{31} \lambda_{11}+\varepsilon_{11} ; \\
& h_{12}=\beta_{01}+\beta_{11}[w(1-\text { mtax })]+\beta_{21} y+\beta_{31} \lambda_{12}+\varepsilon_{12} \\
& h_{21}=\beta_{021}+\beta_{121}[w(1-\text { mtax })]+\beta_{221} y+\beta_{321} \lambda_{21}+\varepsilon_{21} \\
& h_{22}=\beta_{022}+\beta_{122}[w(1-\text { mtax })]+\beta_{222} y+\beta_{322} \lambda_{22}+\varepsilon_{22} \\
& h_{3}=\beta_{03}+\beta_{13}[w(1-\text { mtax })]+\beta_{23} y+\beta_{33} \lambda_{11}+\varepsilon_{3} \\
& E\left(\varepsilon_{i j} \mid X\right)=0 \\
& \text { Let } \varepsilon=\left\{\varepsilon_{11}, \varepsilon_{12}, \varepsilon_{21}, \varepsilon_{22}, \varepsilon_{3}\right\}^{\prime} \text { and } E\left(\varepsilon \varepsilon^{\prime} \mid X\right)=\Omega ;
\end{aligned}
$$

where the $\lambda s$ are the inverse Mill's ratios estimated separately for week data, time-use data and annual data using the assumption of normal errors and the following explanatory variables: an intercept variable, age, age squared, number of children in the household, if the respondent was single, if someone in the household had health problems, the tax assessed value of the house ${ }^{11}$ of the household, years of schooling, and if summer ${ }^{12}$.

$\mathrm{X}$ is a vector of instruments: An intercept variable, age, age squared, if single, number of adults in household, number of children in the household, if someone in the household had health problems, if summer, floor area in square meters of house/apartment, tax assessed value of house, wage rate, years of schooling, and the $\lambda: s$. 
The covariance matrix $\Omega$ is through the $\lambda$ :s a function of data, and ideally the model should have been estimated taking this into account. When doing this in a GMM framework, the estimated weight matrix in the efficient GMM step occasionally became nonpositive definite. The problem seemed to be that the number of observations contributing to each equation was rather different. This is a small sample problem and to bypass it the assumption of homoskedasticity was imposed. This implies that the model was estimated by 3SLS. The estimates are still consistent and hopefully they are more efficient than the 2SLS estimates that were used in the first step of the GMM (3SLS) procedure. ${ }^{13}$

To take account of the variability introduced in the imputation procedure, the model was estimated by bootstrapping the 3SLS estimates. More specifically the estimation proceeded in the following way. A bootstrap sample was drawn from the original data set. The imputation regression was estimated and missing virtual income observations were imputed. The model was then estimated by 3SLS. This sequence was repeated 1000 times. The estimates presented are the means from the bootstrap distribution and the corresponding $95 \%$ percentile bootstrap confidence intervals. $^{14}$

\section{Estimation results}

In comparing the estimates of the equations using alternative measures of hours of work one must keep in mind that they refer to different time spans. When model (2) was estimated annual hours were divided by 50 to facilitate comparison with estimates based on weekly data. The time-use equations were, however, estimated using data on hours per day. It is not obvious how the time-use data based estimates should be transformed to compare with the 
other estimates. Noting that the equations of model (2) were estimated with compensation for the selection into having a job (or more precisely, working positive hours), and that the estimated equations thus should apply both to working and non-working, one approach is to weight the estimates for weekdays with 5 and those for weekends with 2. (Estimates using this approach are presented in the second last column of Tables 5 and 7 below.)

However, the share of the population that works in weekends is relatively small (c f Table 4), and a linear model such as the fourth equation of model (2) might not be such a good model to capture the labour supply behavior in weekends of the entire population. Weighting the weekend estimates with 2 will probably give too much weight to these estimates. An alternative is then to note that most people only work in weekdays and thus only compare with the weekday estimates multiplied by 5 . The fact that the weekend estimates are based on rather few observations also supports a decision to use this approach. Although estimates that facilitate both kinds of comparisons will become presented below, the preferred approach is the second one. ${ }^{15}$

Table 5 exhibits bootstrapped 3SLS estimates of model (2) by gender and data type. Let's first compare the mean estimates for weekdays with those for weekends (The middle columns in Table 5.). The marginal wage rate effects are positive for weekdays but negative for weekends. This is true both for males and females. The income effect is negative for weekdays. For males it is also negative for weekends but for females it is positive. All weekend estimates are larger in absolute value. These mean differences between weekdays and weekends are significant (Table 6). We thus conclude that behavior on weekdays are more or less in line with what we have seen in other studies, while weekend behavior with respect to wage rate and income changes is very different. 
Next turn to a comparison of wage rate effects across data types. Annual hours data give the smallest mean estimates, for females it is negative and for males virtually zero. Data on hours worked last week give the highest estimates. If we compare to time-use data based estimates for weekdays we find that they are positive and for males of the same magnitude as the weekly hours estimate $\left(5^{*} 0.006=0.030\right)$. Based on this comparison we thus find the same ranking of the data sources for both gender: Weekly hours the highest estimates and annual data the smallest with time-use data in between. If we prefer to weight in results for weekends the resulting time-use data estimates turn negative and the time-use data estimates don't differ that much from those using annual data. However, for the reasons already given we don't put much confidence in this comparison.

The bootstrap percentile confidence intervals (in italics) are in most cases so wide that it is difficult to draw firm conclusions about the differences in estimates across data types. A more formal test would be useful. Tests were set up in the following way. In each bootstrap replication a number of t-scores were computed. Each t-score was a difference between two estimates, for instance the estimates of the net wage rate effects using annual and time-use data, divided by a large sample estimate of the standard error of the difference. This was done for the estimates of the wage rate and income effects and for the data comparisons week data/time-use data weighting weekday and weekend results, annual data/ time-use data weighting weekday and weekend results, week data/annual data, weekday data/weekend data, week data/time-use data for weekdays and annual data/time-use data for weekdays. Under the null hypothesis that there is no difference in effects due to data source these t-scores are pivotal statistics and the distributions of these statistics have zero mean. Table 6 displays the means of the bootstrap distributions. With a few exceptions they are not close to zero. Do they 
differ so much from zero that the differences cannot be a result of the fact that we do not have the true distribution, only an estimate based on 1000 bootstrap replications? The answer is yes, because the t-scores for the test of zero mean are very high (see Table 6). We thus conclude that with the model and estimation method used annual data computed from the response to a question about normal hours of work give the smallest estimates, even negative estimates, while data on hours worked last week and time-use data of hours worked in weekdays give significantly higher estimates.

The mean estimates of the income effects are all negative with the exception of the estimate for female work hours in weekends. Annual data give the largest estimates in absolute value. For males time-use data from weekdays give an estimate of approximately the same size, while the estimate for females is smaller. Compared to annual data weekly data give mean estimates closer to zero.

The confidence intervals for the selection effects all include the point zero, except with annual data. Thus, only in this case the selection effect is significantly different from zero.

How robust are these results? Is it possible that measurement errors in the normal weekly hours variable, that was used to compute the wage rates, create these results? One might argue that the instrumentation of the wage rate variable should take care of any endogeneity created by measurement errors, but it might take much larger samples than used in this study to eliminate the effects of such errors. If that is true one might expect measurement errors to create a negative bias in the wage rate effect in particular for the annual hours equation, where we would have the same measurement error in the denominator of the hourly wage rate as in the dependent variable. To investigate this possibility the model was also estimated using the 
monthly wage rate that should be less sensitive to these errors. The results are displayed in Tables 7 and 8 . The estimates of the wage rate effects change because of the scale difference between a monthly wage rate and an hourly wage rate, but the ranking of the data sources by

these estimates become the same as in the previous case. ${ }^{16}$ The estimates of the income effects are virtually the same as before. Our conclusions thus do not depend on the choice of wage rate measure.

\section{Conclusions}

The results from this study suggest that the measure of hours worked matters. Marginal effects (and elasticities) depend on the measures chosen. Normal weekly hours is a measure that is smoothed and concentrated to contracted hours compared to hours worked last week and time-used data for weekdays. The latter two measures give larger wage rate effects compared to annual hours computed from normal weekly hours. There is no clear ranking between last week data and time-use data.

Although the sample of people working in weekends is very small our results demonstrate that market work in weekends does not depend on wage rates and incomes in the same way as does market work in weekdays. The marginal wage rate effect is strongly negative for weekends. The relative size of the wage rate effect using time-use data might change if labour supply in weekends is considered jointly with the weekday supply, but the share of people working in weekends is so small that the resulting decrease in magnitude is not likely to be large. 
The estimates of the income effects are negative, so leisure is a normal good. Judged by these estimates there is no clear ranking between all data sources, but one result is that annual data give large estimates in absolute value for both gender. Annual data thus give wage rate effects rather close to zero but high negative income effects. With these data the income effect will dominate. This is not the case with the other two types of data.

Our results also show that the confidence intervals are rather wide. This implies that two different samples could just by chance give rather different estimates. This is not only a result of our imputation procedure. A larger sample would improve the precision of the estimates, but the wide intervals might also suggest that the model used is too simple. If the same study was to become repeated on more numerous data one should probably use a model that more explicitly captures heterogeneity in preferences.

Why would data based on normal hours tend to give smaller estimates of the wage rate effect than the alternative data types? The result that the two alternative wage rate variables give almost the same results except for a scale difference suggests that the problem does not lie in the construction of the wage rate measures. A reasonable hypothesis is that estimates based on normal weekly hours tend to smooth or leave out overtime, days with unusually long or short hours, market work at home, etc. There is thus less variability in data for normal weekly hours. This is, however, not enough. There must also be a correlation between the net wage rate and the under/over reporting. If people with high wages work long hours but tend to underreport those in regular surveys, and people with low wages work short hours but tend to over report those, then the kind of result we have got could emerge. Future research about measurement errors in surveys would have to tell us if such a correlation can be verified. 
Although the estimates are uncertain, the differences in estimates are of a magnitude that is policy relevant. This suggests that measurement issues cannot be ignored in applied work. More work about the properties of measurement errors and their impact on the estimates of key policy parameters is highly desirable. 


\section{References}

Blomquist, S., 1996, Estimation methods for male labour supply functions. How to take care of nonlinear taxes, Journal of Econometrics, 70, 383-405.

Blundell R. and T. MaCurdy, 1999, Labor Supply a Review of Alternative Approaches, in O.C. Ashenfelter and D. Card, eds., Handbook of Labor Economics, Vol. 3A, (North-Holland, Amsterdam)

Brownstone, D. and R.G. Valletta, 1996, Modeling earnings measurement error: A multiple imputation approach, The Review of Economics and Statistics, 78:4, 705-717

Carlin P.S. \& L. Flood, 1997, Do children affect the labour supply of Swedish men? Time diary vs. survey data", Labour Economics, Vol 4, No 2, 167-183

Flood, L., N.A Klevmarken and P. Olovsson, 1997, Household Market and Nonmarket Activities (HUS), Volumes III-VI, (Department of Economics, Uppsala University, Uppsala)

Flood, L. and T. MaCurdy, 1992, Work disincentive effects of taxes: an empirical analysis of Swedish men, Carnegie-Rochester Conference Series on Public Policy 37, 239-278

Juster F. Th. and F.P. Stafford, 1991, The allocation of time: Empirical findings, behavioural models and problems of measurement, Journal of Economic Literature. 29, 471-522 
Klevmarken, N.A., 1999, Microeconomic Analysis of Time-use Data: Did we reach the Promised Land? in J. Merz and M. Ehling, eds., Time-use - Research, Data and Policy, (NOMOS Verlagsgesellschaft, Baden-Baden)

Klevmarken, N.A. and P. Olovsson, 1993, Household Market and Nonmarket Activities. Procedures and Codes 1984-1991, Vol I and II. (The Industrial Institute for Economic and Social Research, Almquist \& Wiksell International, Stockholm)

Leete L. and J.B. Schor, 1994, Assessing the time-squeeze hypothesis: Hours worked in the United States 1969-89, Industrial Relations 33, 1, 25-43

Schwierz, C. 2003, The Effects of Taxes and Socioeconomic Variables on Market Work and Home Production in Norway in the Years 1970 to 2000, Memorandum 33/2003, Department of Economics, University of Oslo 
Table 1. Alternative estimates of weekly work hours by gender 1983/84 and 1992/93

\begin{tabular}{cccccccccc}
\hline 1983 & & 1984 & & 1992 & & 1993 \\
$m$ & $f$ & $m$ & $f$ & $m$ & $f$ & $m$ & $f$
\end{tabular}

\section{"Survey estimates"}

HUS data

Annual hours/weeks worked
$41.8 \quad 40.3$
$41.9 \quad 35.0$
$(0.2) \quad(0.3)$
(0.3) (0.3)

$5^{*}$ hours latest workday

$43.0 \quad 38.5$

$44.5 \quad 38.9$

(0.3) (0.4)

(0.4) $(0.5)$

Normal hours incl. secondary jobs*

$41.8 \quad 35.0$

$42.5 \quad 37.5$

(0.5) (0.5)

(0.2) $(0.2)$

Latest week worked

41.933 .6

(0.4) $(0.4)$

Labour force Survey. Statistics Sweden

All in work and temporary absent, 16-64 years old

$35.1 \quad 25.7$

$34.6 \quad 26.1$

All in work 16-64 years old

$40.6 \quad 31.7$

39.932 .5

Employed 16-64(74) years old

$39.7^{\#} \quad 31.4^{\#}$

$38.6 \quad 32.2$

$\underline{\text { Time-use estimates }}$

Excluding break time

All 20-64 years old

$25.6 \quad 17.6$

33.624 .7

(0.7) (0.6)

If normal hours $>0$

$30.5 \quad 22.9$

36.629 .1

(0.8) (0.7)

(0.9) (0.9)

Including break time

All 20-64 years old

$29.3 \quad 20.1$

$42.5 \quad 31.4$

(0.8) (0.7)

(1.1) (1.0)

If normal hours $>0$

$$
\begin{array}{ll}
35.0 & 26.2 \\
(0.9) & (0.8)
\end{array}
$$

(1.2) (1.1)

*Employed only. The questions used were phrased: "On average, how many hours per week are you currently working at your primary job, including both paid and unpaid overtime", "Do you have another job in addition to your primary job?" and if YES, “How many hours do you spend on your other job(s)?” (Replies given per day, week, month or year).

\# 16-74 years old

Note 1. The estimates for "Annual hours/weeks worked" were obtained using a sequence of questions about weeks worked in full-time and part-time work last year and about the average number of hours during those fulltime and part-time weeks respectively.

Note 2. The hours of work question in the Labour Force surveys were: "The question which follows applies to a certain week, Monday the ..... to Sunday the ..., that is week no .... How many hours did you work that week in your main job? How many hours in any secondary job?" 
Note 3. Time-use estimates include the sum of work hours in primary and secondary activities, but market work as a secondary activity is very small. Secondary jobs are also included. Breaks include lunch, coffee breaks, personal errands and telephone calls while at work. The sample is limited to respondents who gave two complete time-use interviews (one work day and one weekend day). If the respondent had a job at the time for the workday time-use interview and had not been away for more than 8 weeks, the respondent was classified as in work or temporarily absent.

Source: Klevmarken(1999) 
Table 2. Correlation matrix for alternative measures of hours worked, males less than 65 years of age.

Including zero observations.

\begin{tabular}{|l|l|l|l|l|l|}
\hline & Week hours 1 & Week hours 2 & $\begin{array}{l}\text { Time-use } \\
\text { weekday }\end{array}$ & $\begin{array}{l}\text { Time-use } \\
\text { weekend }\end{array}$ & $\begin{array}{l}\text { Annual } \\
\text { hours }\end{array}$ \\
\hline Week hours 1 & 1.000 & 0.436 & 0.498 & 0.155 & 0.590 \\
\hline Week hours 2 & & 1.000 & 0.480 & 0.173 & 0.550 \\
\hline $\begin{array}{l}\text { Time-use } \\
\text { weekday }\end{array}$ & & & 1.000 & 0.087 & 0.481 \\
\hline $\begin{array}{l}\text { Time-use } \\
\text { weekend }\end{array}$ & & & & 1.000 & 0.126 \\
\hline Annual hours & & & & & 1.000 \\
\hline
\end{tabular}

Note: 739 observations

Excluding zero observations

\begin{tabular}{|l|l|l|l|l|l|}
\hline & Week hours 1 & Week hours 2 & $\begin{array}{l}\text { Time-use } \\
\text { weekday }\end{array}$ & $\begin{array}{l}\text { Time-use } \\
\text { weekend }\end{array}$ & $\begin{array}{l}\text { Annual } \\
\text { hours }\end{array}$ \\
\hline Week hours 1 & 1.000 & 0.365 & 0.214 & 0.268 & 0.398 \\
\hline Week hours 2 & & 1.000 & 0.194 & 0.220 & 0.370 \\
\hline $\begin{array}{l}\text { Time-use } \\
\text { weekday }\end{array}$ & & & 1.000 & -0.033 & 0.215 \\
\hline $\begin{array}{l}\text { Time-use } \\
\text { weekend }\end{array}$ & & & & 1.000 & -0.030 \\
\hline Annual hours & & & & & 1.000 \\
\hline
\end{tabular}


Table 3. Correlation matrix for alternative measures of hours worked, females less than 65 years of age.

Including zero observations.

\begin{tabular}{|l|l|l|l|l|l|}
\hline & Week hours 1 & Week hours 2 & $\begin{array}{l}\text { Time-use } \\
\text { weekday }\end{array}$ & $\begin{array}{l}\text { Time-use } \\
\text { weekend }\end{array}$ & $\begin{array}{l}\text { Annual } \\
\text { hours }\end{array}$ \\
\hline Week hours 1 & 1.000 & 0.465 & 0.497 & 0.125 & 0.554 \\
\hline Week hours 2 & & 1.000 & 0.479 & 0.227 & 0.602 \\
\hline $\begin{array}{l}\text { Time-use } \\
\text { weekday }\end{array}$ & & & 1.000 & 0.126 & 0.483 \\
\hline $\begin{array}{l}\text { Time-use } \\
\text { weekend }\end{array}$ & & & & 1.000 & 0.093 \\
\hline Annual hours & & & & & 1.000 \\
\hline
\end{tabular}

Note: 776 observations

Excluding zero observations

\begin{tabular}{|l|l|l|l|l|l|}
\hline & Week hours 1 & Week hours 2 & $\begin{array}{l}\text { Time-use } \\
\text { weekday }\end{array}$ & $\begin{array}{l}\text { Time-use } \\
\text { weekend }\end{array}$ & $\begin{array}{l}\text { Annual } \\
\text { hours }\end{array}$ \\
\hline Week hours 1 & 1.000 & 0.562 & 0.389 & -0.004 & 0.504 \\
\hline Week hours 2 & & 1.000 & 0.370 & 0.036 & 0.521 \\
\hline $\begin{array}{l}\text { Time-use } \\
\text { weekday }\end{array}$ & & & 1.000 & 0.261 & 0.268 \\
\hline $\begin{array}{l}\text { Time-use } \\
\text { weekend }\end{array}$ & & & & 1.000 & -0.117 \\
\hline Annual hours & & & & & 1.000 \\
\hline
\end{tabular}


Table 4 Share reporting market work and mean hours per day in weekday and weekends, by gender

\begin{tabular}{|l|l|l|l|l|l|l|}
\hline & \multicolumn{3}{|l|}{$\begin{array}{l}\text { Respondents }<65 \text { years of age that participated in two } \\
\text { time-use interviews }\end{array}$} & $\begin{array}{l}\text { Respondents }<65 \text { years of } \\
\text { age that participated in two } \\
\text { time-use interviews and } \\
\text { reported normal hours of } \\
\text { work>0 }\end{array}$ \\
\hline & $\begin{array}{l}\text { Share } \\
\text { reporting } \\
\text { market } \\
\text { work in } \\
\text { weekdays }\end{array}$ & $\begin{array}{l}\text { Share } \\
\text { reporting } \\
\text { market } \\
\text { work in } \\
\text { weekends }\end{array}$ & $\begin{array}{l}\text { Mean hours } \\
\text { per day in } \\
\text { weekdays }\end{array}$ & $\begin{array}{l}\text { Mean hours } \\
\text { per day in } \\
\text { weekends }\end{array}$ & $\begin{array}{l}\text { Share } \\
\text { reporting } \\
\text { market } \\
\text { work in } \\
\text { weekdays }\end{array}$ & $\begin{array}{l}\text { Share } \\
\text { reporting } \\
\text { market } \\
\text { work in } \\
\text { weekends }\end{array}$ \\
\hline Males & 0.623 & 0.196 & 5.7 & 1.2 & 0.715 & 0.218 \\
\hline Females & 0.526 & 0.132 & 4.3 & 0.8 & 0.636 & 0.149 \\
\hline
\end{tabular}


Table 5 Bootstrap 3SLS estimates of labour supply functions by type of data, using hourly earnings

\begin{tabular}{|c|c|c|c|c|c|}
\hline Variables & Weekly hours & $\begin{array}{l}\text { Time-use } \\
\text { hours } \\
\text { weekdays }\end{array}$ & $\begin{array}{l}\text { Time-use } \\
\text { hours } \\
\text { weekends }\end{array}$ & $\begin{array}{l}\text { Time-use } \\
\text { hours } \\
\text { weeks }\end{array}$ & $\begin{array}{l}\text { Annual } \\
\text { hours }\end{array}$ \\
\hline \multicolumn{6}{|l|}{ Males } \\
\hline Intercept & $\begin{array}{ll}40.80 & \\
37.31 & 44.34\end{array}$ & $\begin{array}{ll}8.18 & \\
6.99 & 9.34\end{array}$ & $\begin{array}{ll}2.04 & \\
-6.559 .61\end{array}$ & & $\begin{array}{ll}44.39 & \\
37.00 & 50.84\end{array}$ \\
\hline$W(1-m t a x)$ & $\begin{array}{ll}0.027 & \\
-0.009 & 0.070\end{array}$ & $\begin{array}{ll}0.006 & \\
-0.002 & 0.017\end{array}$ & $\begin{array}{ll}-0.022 & \\
-0.054 & 0.015\end{array}$ & $\begin{array}{ll}-0.012 & \\
-0.103 & 0.083\end{array}$ & $\begin{array}{ll}-0.000 & \\
-0.111 & 0.121\end{array}$ \\
\hline Virtual inc ${ }^{*}$ & $\begin{array}{ll}-0.066 & \\
-0.000 & 0.024\end{array}$ & $\begin{array}{ll}-0.017 & \\
-0.046 & 0.010\end{array}$ & $\begin{array}{ll}-0.028 & \\
-0.080 & 0.013\end{array}$ & $\begin{array}{ll}-0.143 & \\
-0.326 & 0.011\end{array}$ & $\begin{array}{l}-0.084 \\
-0.178-0.004\end{array}$ \\
\hline Lambda & $\begin{array}{ll}-2.89 & \\
-8.28 & 3.17\end{array}$ & $\begin{array}{ll}-1.17 & \\
-3.20 & 0.735\end{array}$ & $\begin{array}{rr}3.33 & \\
-1.94 & 9.44\end{array}$ & & $\begin{array}{l}-8.21 \\
-16.01-0.946\end{array}$ \\
\hline $\begin{array}{l}\text { Nobs }{ }^{* *} \\
\text { hours }>0 \\
\text { interv. } 1 \text {, } \\
\text { Interv. } 2 \\
\text { Weekdays } \\
\text { weekends }\end{array}$ & $\begin{array}{l}435 \\
474\end{array}$ & 448 & 128 & & 515 \\
\hline Total nobs & 718 & 718 & 718 & & 718 \\
\hline \multicolumn{6}{|l|}{ Females } \\
\hline Intercept & $\begin{array}{ll}34.78 & \\
31.23 & 38.30 \\
\end{array}$ & $\begin{array}{l}7.67 \\
6.40\end{array}$ & $\begin{array}{ll}5.10 & \\
-8.34 & 18.29 \\
\end{array}$ & & $\begin{array}{ll}39.38 & \\
30.14 & 47.84 \\
\end{array}$ \\
\hline $\mathrm{W}(1-\mathrm{mtax})$ & $\begin{array}{ll}0.026 & \\
-0.022 & 0.084\end{array}$ & $\begin{array}{ll}0.002 & \\
-0.011 & 0.015\end{array}$ & $\begin{array}{ll}-0.018 & \\
-0.047 & 0.012\end{array}$ & $\begin{array}{ll}-0.026 & \\
-0.128 & 0.072\end{array}$ & $\begin{array}{ll}-0.034 & \\
-0.176 & 0.122\end{array}$ \\
\hline Virtual inc ${ }^{*}$ & $\begin{array}{ll}-0.063 & \\
-0.217 & 0.079\end{array}$ & $\begin{array}{ll}-0.004 & \\
-0.051 & 0.038\end{array}$ & $\begin{array}{ll}0.028 & \\
-0.043 & 0.096\end{array}$ & $\begin{array}{ll}0.033 & \\
-0.259 & 0.308\end{array}$ & $\begin{array}{ll}-0.083 \\
-0.2180 .068\end{array}$ \\
\hline Lambda & $\begin{array}{ll}-4.68 & \\
-10.00 & 1.06 \\
\end{array}$ & $\begin{array}{ll}-0.882 & \\
-2.90 & 1.05 \\
\end{array}$ & $\begin{array}{ll}0.292 & \\
-7.85 & 8.60 \\
\end{array}$ & & $\begin{array}{ll}-6.83 & \\
-12.34 & -0.48 \\
\end{array}$ \\
\hline $\begin{array}{l}\text { Nobs }{ }^{* *} \\
\text { hours }>0 \\
\text { interv. 1, } \\
\text { Interv. } 2 \\
\text { Weekdays } \\
\text { weekends }\end{array}$ & $\begin{array}{l}419 \\
453\end{array}$ & 399 & 92 & & 487 \\
\hline Total nobs & 750 & 750 & 750 & & 750 \\
\hline
\end{tabular}

*1000 SEK. $\quad{ }^{* *}$ These numbers vary a little between bootstrap drawings. The numbers given are from a case using the original data.

Note: The table gives the means and 95\% confidence intervals of the bootstrap distribution of the slope parameters. 
Table 6 Pair wise comparisons of differences in net wage rate and income effects, using hourly earnings

\begin{tabular}{|l|l|l|l|l|}
\hline Comparison & Males & Females \\
\hline & Mean & \multicolumn{2}{c|}{$\begin{array}{c}\text { Test of zero } \\
\text { mean } \\
\text { mean }\end{array}$} \\
\hline $\begin{array}{l}\text { Differences in net wage } \\
\text { rate effects }\end{array}$ & & Mean & \\
\hline Week data/Time-use & 1.766 & 32.005 & 2.271 & 29.920 \\
\hline Annual data//Time-use & 0.196 & 3.894 & -.157 & -3.124 \\
\hline Week data/ Annual data & 0.876 & 17.526 & 1.247 & 26.114 \\
\hline Weekday/Weekend & 4.012 & 51.329 & 3.917 & 44.992 \\
\hline Week/Time-use weekday & -0.984 & -24.819 & 1.176 & 20.320 \\
\hline Annual/Time-use weekday & -1.348 & -29.488 & -0.605 & -11.699 \\
\hline $\begin{array}{l}\text { Differences in virtual } \\
\text { income effects }\end{array}$ & & & & \\
\hline Week data/Time-use & 1.580 & 30.164 & -1.469 & -21.391 \\
\hline Annual data/ /Time-use & 0.365 & 12.116 & 0.313 & 8.894 \\
\hline Week data/ Annual data & 0.596 & 11.890 & 0.490 & 9.920 \\
\hline Weekday/Weekend & 1.002 & 14.825 & -2.253 & -27.092 \\
\hline Week/Time-use weekday & 0.739 & 13.591 & -0.348 & -5.239 \\
\hline Annual/Time-use weekday & 0.522 & 9.057 & -0.526 & -7.757 \\
\hline
\end{tabular}

Note 1: These tests apply to the same models, data sets and estimation method as in Table 5. Mean is the mean of the bootstrap distribution of pair wise differences in estimates standardized by an estimated large sample standard deviation. Test of zero mean is the t-score obtained by dividing the mean by the standard deviation of the bootstrap distribution and multiplying by the square root of the number of bootstrap replications (1000).

Note2: In the comparisons Week/Time-use weekday and Annual/Time-use weekday hours worked in a weekday have been multiplied by 5 . 
Table 7 Bootstrap 3SLS estimates of labour supply functions by type of data, using monthly earnings.

\begin{tabular}{|c|c|c|c|c|c|}
\hline Variables & Weekly hours & $\begin{array}{l}\text { Time-use } \\
\text { hours } \\
\text { weekdays }\end{array}$ & $\begin{array}{l}\text { Time-use } \\
\text { hours } \\
\text { weekends }\end{array}$ & $\begin{array}{l}\text { Time-use } \\
\text { hours } \\
\text { weeks }\end{array}$ & $\begin{array}{l}\text { Annual } \\
\text { hours }\end{array}$ \\
\hline \multicolumn{6}{|l|}{ Males } \\
\hline Intercept & $\begin{array}{ll}41.266 & \\
37.83 \quad 44.51\end{array}$ & $\begin{array}{ll}8.216 & \\
7.12 \quad 9.32 \\
\end{array}$ & $\begin{array}{l}2.094 \\
-6.45-9.89\end{array}$ & & $\begin{array}{l}44.524 \\
37.6750 .77\end{array}$ \\
\hline $\mathrm{W}(1-\operatorname{mtax})$ & $\begin{array}{ll}0.129 & \\
-0.077 & 0.364 \\
\end{array}$ & $\begin{array}{ll}0.035 & \\
-0.015 & 0.098\end{array}$ & $\begin{array}{ll}-0.139 & \\
-0.325 & 0.062 \\
\end{array}$ & $\begin{array}{ll}-0.102 & \\
-0.574 & 0.412 \\
\end{array}$ & $\begin{array}{ll}-0.009 & \\
-0.637 & 0.693\end{array}$ \\
\hline Virtual inc* & $\begin{array}{ll}-0.065 & \\
-0.170 & 0.028 \\
\end{array}$ & $\begin{array}{ll}-0.018 & \\
-0.046 & 0.009\end{array}$ & $\begin{array}{ll}-0.027 & \\
-0.076 & 0.015 \\
\end{array}$ & $\begin{array}{ll}-0.142 & \\
-0.328 & 0.014\end{array}$ & $\begin{array}{ll}-0.084 & \\
-0.173 & -0.000\end{array}$ \\
\hline Lambda & $\begin{array}{l}-3.066 \\
-8.8793 .107\end{array}$ & $\begin{array}{ll}-1.198 & \\
-3.269 & 0.709 \\
\end{array}$ & $\begin{array}{ll}3.323 & \\
-2.055 & 9.274 \\
\end{array}$ & & $\begin{array}{ll}-8.302 & \\
-16.049 & -1.256 \\
\end{array}$ \\
\hline $\begin{array}{l}\text { Nobs** } \\
\text { hours }>0 \\
\text { Interv. } 1 \\
\text { Interv. } 2 \\
\text { Weekdays } \\
\text { Weekends }\end{array}$ & $\begin{array}{l}436 \\
475\end{array}$ & 448 & 128 & & 516 \\
\hline Total nobs & 718 & 718 & 718 & & 718 \\
\hline \multicolumn{6}{|l|}{ Females } \\
\hline Intercept & $\begin{array}{l}34.57 \\
30.96\end{array}$ & $\begin{array}{c}7.61 \\
6.26\end{array}$ & $\begin{array}{l}5.01 \\
-8.27\end{array}$ & & $\begin{array}{l}37.56 \\
28.55\end{array}$ \\
\hline $\mathrm{W}(1-\operatorname{mtax})$ & $\begin{array}{ll}0.202 & \\
-0.130 & 0.531 \\
\end{array}$ & $\begin{array}{ll}0.025 & \\
-0.061 & 0.117\end{array}$ & $\begin{array}{ll}-0.108 & \\
-0.296 & 0.083\end{array}$ & $\begin{array}{ll}-0.090 & \\
-0.758 & 0.575\end{array}$ & $\begin{array}{ll}-0.002 & \\
-0.874 & 0.926\end{array}$ \\
\hline Virtual inc* & $\begin{array}{ll}-0.073 & \\
-0.228 & 0.072\end{array}$ & $\begin{array}{ll}-0.008 & \\
-0.061 & 0.038\end{array}$ & $\begin{array}{ll}0.029 & \\
-0.042 & 0.098\end{array}$ & $\begin{array}{ll}0.015 & \\
-0.293 & 0.297\end{array}$ & $\begin{array}{ll}-0.086 & \\
-0.214 & 0.064\end{array}$ \\
\hline Lambda & $\begin{array}{ll}-4.68 & \\
-9.90 & 0.82 \\
\end{array}$ & $\begin{array}{l}-0.874 \\
-2.99 \\
\end{array}$ & $\begin{array}{ll}0.322 & \\
-7.71 & 9.05 \\
\end{array}$ & & $\begin{array}{ll}-6.49 & \\
-11.88 & -1.34 \\
\end{array}$ \\
\hline $\begin{array}{l}\text { Nobs }{ }^{* *} \\
\text { hours }>0 \\
\text { Interv. } 1 \\
\text { Interv. } 2 \\
\text { Weekdays } \\
\text { Weekends }\end{array}$ & $\begin{array}{l}398 \\
443\end{array}$ & 404 & 89 & & 472 \\
\hline Total nobs & 679 & 679 & 679 & & 679 \\
\hline
\end{tabular}

${ }^{*} 1000$ SEK. ${ }^{* *}$ These numbers vary a little between bootstrap drawings. The numbers given are from a case using the original data.

Note: The table gives the means and $95 \%$ confidence intervals of the bootstrap distribution of the slope parameters.. 
Table 8 Pair wise comparisons of differences in net wage rate and income effects, using monthly earnings

\begin{tabular}{|l|l|l|l|c|}
\hline Comparison & Males & \multicolumn{2}{l|}{} \\
\hline & Mean & $\begin{array}{l}\text { t-test of zero } \\
\text { mean }\end{array}$ & Mean & $\begin{array}{l}\text { t-test of zero } \\
\text { mean }\end{array}$ \\
\hline $\begin{array}{l}\text { Differences in net wage } \\
\text { rate effects }\end{array}$ & & & & \\
\hline Week data/Time-use & 1.808 & 32.692 & 1.838 & 21.135 \\
\hline Annual data//Time-use & 0.307 & 6.108 & 0.228 & 4.560 \\
\hline Week data/ Annual data & 0.763 & 15.720 & 0.740 & 15.510 \\
\hline Weekday/Weekend & 4.360 & 56.005 & 3.989 & 48.859 \\
\hline Week/Time-use weekday & -1.097 & -28.243 & 1.007 & 16.048 \\
\hline Annual/Time-use weekday & -1.349 & -29.699 & -0.211 & -3.499 \\
\hline $\begin{array}{l}\text { Differences in virtual } \\
\text { income effects }\end{array}$ & & & & \\
\hline Week data/Time-use & 1.577 & 30.477 & -1.290 & -18.294 \\
\hline Annual data//Time-use & 0.378 & 12.353 & 0.197 & 6.223 \\
\hline Week data/ Annual data & 0.614 & 12.176 & 0.340 & 7.023 \\
\hline Weekday/Weekend & 0.833 & 11.945 & -2.365 & -29.528 \\
\hline Week/Time-use weekday & 0.800 & 15.011 & -0.271 & -2.698 \\
\hline Annual/Time-use weekday & 0.582 & 10.237 & -0.451 & -6.153 \\
\hline
\end{tabular}

Note1: These tests apply to the same models, data sets and estimation method as in Table 7. Mean is the mean of the bootstrap distribution of pair wise differences in estimates standardized by an estimated large sample standard deviation. Test of zero mean is the t-score obtained by dividing the mean by the standard deviation of the bootstrap distribution and multiplying by the square root of the number of bootstrap replications (1000).

Note2: In the comparisons Week/Time-use weekday and Annual/Time-use weekday hours worked in a weekday have been multiplied by 5 . 

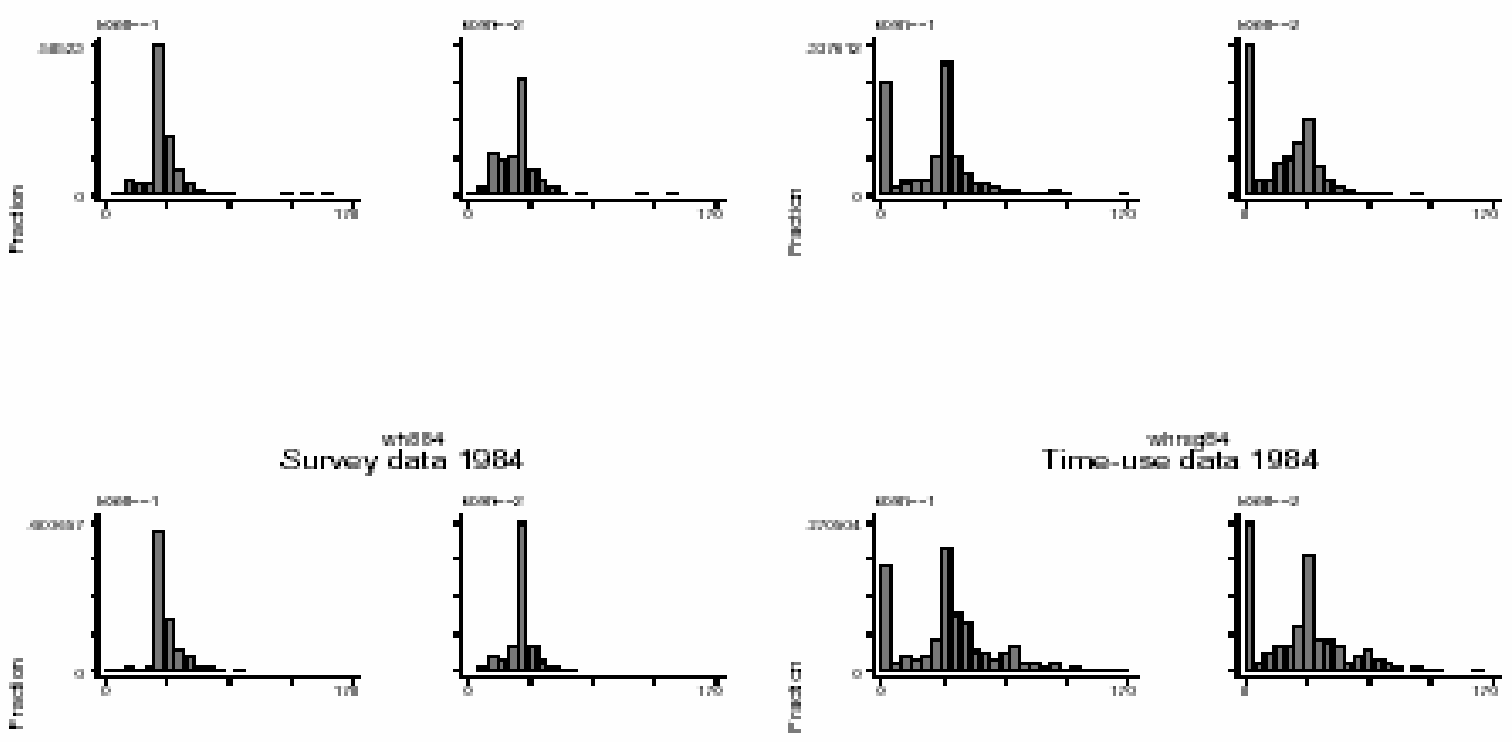

data 1984

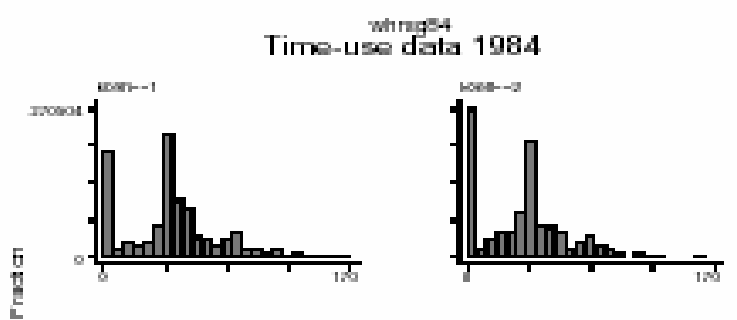

Survey data 1993

Time-use data 1993

Figure 1 Weekly workhours by gender and data type

Source: Klevmarken(1999) 


\section{${ }^{1}$ One recent exception is Schwierz (2003).}

${ }^{2}$ For this reason one might also argue that work time from a time-use diary will not only include time in the regular "white" market but also in the "black" market.

${ }^{3}$ They also argued that Juster and Stafford(1991) had "not corrected for the fact that in the 1965 sample all household heads were employed. This is especially important because 1981 was a recession year" (p. 41).

${ }^{4}$ The joint dependence of spouses' market work is ignored in this paper.

${ }^{5}$ Many labor contracts had 65 as an upper age limit and the social security system was designed for retirement at the age of 65 .

${ }^{6}$ There is also a question about number of hours worked on the latest day of work. To increase the precision of the estimate, the measure used to compute the hourly wage rate was actually a weighted average of the response to the question about normal hours and that about hours in the latest day of work. (In the subsequent analysis of normal hours of work only the response to the question about normal hours was used.)

${ }^{7}$ If the household did not own a house the value of this variable was set to zero.

${ }^{8}$ A SAS code with the details of these computations is available from the author on request.

${ }^{9}$ In interpreting Table 4 please note that there are respondents that worked in both kinds of days and respondents that did not work in any of the two kinds of days.

${ }^{10}$ The Christmas and Easter holidays were excluded.

${ }^{11}$ If the respondent did not live in a house the value was put to zero.

${ }^{12}$ Not used with annual hours of work

${ }^{13}$ The 2 SLS estimates usually differed a little from the 3SLS estimates but not so much that the conclusions changed. For this reason the 2SLS estimates are not presented below.

${ }^{14}$ Application of the percentile bootstrap intervals builds on the assumption that the bootstrap distribution is an unbiased estimate of the true distribution of the parameter estimates. An alternative estimation method is to use the multiple imputation approach outlined in Brownstone and Valletta(1996) and large sample formulas.

${ }^{15}$ A completely different approach that facilitates comparison is to assume that the labor supply function is the same for weekdays and weekends. Then a straight forward comparison is obtained by simply multiply the timeuse based estimates by 7 . The model has also been estimated using this assumption. It is, however, a very unrealistic assumption as will become demonstrated below. 
${ }^{16}$ If people work 40 hours per week and there are on average 4.3 weeks per month, the estimated wage rate effects using monthly wages should be reduced by a factor of 0.17 to compare to the estimates in Table 5 . Applying this conversion factor to the estimates of Table 7 gives almost the same estimates as in Table 5 . 